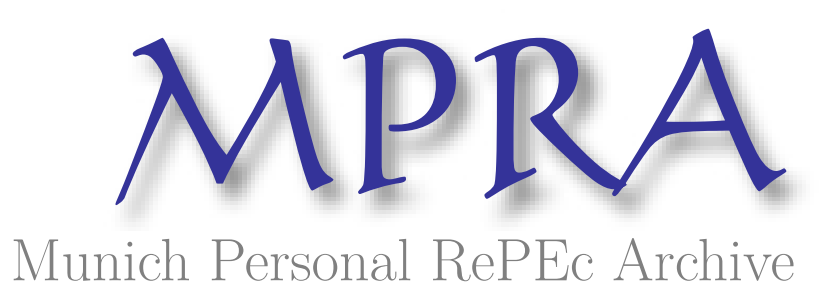

\title{
Quality expectations, reputation, and price
}

Landon, Stuart and Smith, Constance

1998

Online at https://mpra.ub.uni-muenchen.de/9774/

MPRA Paper No. 9774, posted 31 Jul 2008 06:17 UTC 


\title{
Quality Expectations, Reputation and Price*
}

\author{
Stuart Landon and Constance E. Smith (corresponding author) \\ Department of Economics \\ University of Alberta \\ Edmonton, Alberta \\ Canada T6G $2 \mathrm{H} 4$ \\ e-mail: csmith@econ.ualberta.ca
}

JEL L15, D8, M3

tThe authors thank Robin Lindsey, Douglas $\mathrm{S}$. West and two anonymous referees for comments on an earlier dratt as well as william M. Caxter for help in acquiring some of the data. Daisy Ho and Jessica Xu provided efficient research astistance. 


\title{
Quality Expectations, Reputation and Price
}

\begin{abstract}
Abatract
While the theoretical literature on firm reputation is well developed, there exist few empirical studies that quantify the importance of reputation effects. This paper estimates the impact on price of current product quality and reputation using data from the market for Bordeaux wine. A model is proposed in which price is a function of current quality and expected quality, where the latter depends on reputation. Equations determining price and expected quality are estimated jointly. The empirical findings show that the price premium associated with a better reputation far exceeds that associated with improvements in current quality. The impact of reputation on price is disaggregated into individual firm and collective for group) reputation effects and the significance and magnitude of these effects are compared. The results indicate that both types of reputation are important and that, in general, the market values collective reputation indicators only to the extent that they are useful predictors of product quality.
\end{abstract}

Keywords: reputation, product quality, information 


\section{Quality Expectations, Reputation, and Price}

The impact on price of current product quality and reputation are estimated using data from the market for Bordeaux wine. A model is proposed in which price is a function of current quality and expected quality, where the latter depends on reputation. Equations determining price and expected quality are estimated jointly. The empirical findings show that the price premium associated with better individual and collective (or group) reputation far exceeds that associated with improvements in current quality. As well, the market values collective reputation indicators only to the extent that they are useful predictors of product quality.

Keywords: reputation, product quality, information 


\section{Introduction}

When the true quality of a product is not known before purchase, consumers may rely on a firm's reputation to form expectations of the product's quality. In this case, product prices will depend on firm reputation, as shown by klein and Leffler (1981), Shapiro (1983) and Allen (1984). While the theoretical literature on reputation is well developed, there have been few attempts to empirically quantify the magnitude of reputation effects on price or to measure the relative impact on pxice of reputation and current quality.' Jarrell and Peltzman (1985), Borenstein and Zimmerman (1988) and Karpoff and Lott (1993) empirically analyze firm reputation, but they examine the impact of reputation on shareholder wealth or product demand rather than on price. Caves and Greene (1996) show how factors that may affect a consumer's ability to evaluate a firm's reputation (such as previous expexience with the product) influence the correlation between price and quality. Using U.S. data from the nineteenth century, Gorton (1996) examines the relationship between a bank's reputation for default and the discount rate on its debt.

This paper provides empirical estimates of the magnitude of the impact of reputation and current quality on price. By examining the role of reputation in price determination, and compaxing this role to that of current quality, it is possible to infer whether firm reputation provides useful information to consumers and whether consumers use this information to guide their consumption decisions. The results can also be used to 
determine whether a firm that invests in reputation will garner a higher price.

The empirical analysis employs a model in which price depends on both current quality and expected quality, where the latter is a function of reputation. Individual firm data from the market for Bordeaux wine are used to jointly estimate equations determining price and expected quality. ${ }^{2}$ The results show that the impact of reputation on price is approximately 20 times greater than the impact of current quality on price. This suggests a major role for reputation in price determination.

The analysis undertaken below distinguishes between the impact on price of two types of reputation. In the first of these, individual firm reputation, reputation is based on the past quality of a firm's output. This form of reputation is consistent with that used in the theoretical studies of Klein and Leffler (1981), Shapiro (1983) and Allen (1984).

The second type of reputation examined, collective reputation, is similar to a concept suggested by Tirole (1996), and is defined as the average quality produced by a group of firms with which an individual firm can be identified. In a market with a large number of firms, such as the market for Bordeaux wine, it may be very costly for consumers to acquire information on the past quality of the goods produced by all firms. It is typically less costly for consumers to acquire information on collective (or group) quality which can be used as an indicator of the quality of the goods produced by individual firms in the group. For example, a consumer's expectation of the 
quality of the wine made by an individual Bordeaux winemaker may depend on the average quality of all Bordeaux wines."

Several features of the Bordeaux red wine industry make it especially appropriate for an empirical analysis of the relationship between quality, price, and reputation. Wine is a differentiated product and the large number of producers in the industry makes it costly for consumers to obtain full information on the current quality of all individual wines produced. Furthermore, the industry is relatively stable in the sense that there have not been major changes to the product which might reduce consumers' reliance on reputation as a predictor of current quality. As well, Bordeaux wine is characterized by a number of collective or group reputation indicators. Since these indicators (but not their significance) are often provided on wine labels, information on whether a product belongs to a particular group is frequently available at low cost to consumers.

Although a differentiated product, Bordeaux red wines differ in only a relatively small number of characteristics, in contrast to many consumer products which differ in a large number of dimensions and for which it is much more difficult to obtain a single ovexall measure of product quality." Bordeaux wine also exhibits wide price variation. In the two years of individual firm data used below, the price per bottle varies from $\$ 8.92$ to $\$ 302.56$ in 1985 U.S. dollars. Finally, no firm in the Bordeaux wine industry is a large-enough producer to have a significant impact on the market price, a basic assumption of the reputation 
theories of Klein and Leffler (1981) and Shapiro (1983), for example.

The paper is organized as follows. The model is outlined in section 2. In section 3, the data are described and, in section 4. the estimation methodology is reviewed. The impact on expected quality and price of the individual and collective reputation indicator variables is discussed in section 5 . This section also provides a comparison of the effect on price of expected quality and current quality. Concluding comments are presented in section 6 .

\section{The Model}

To examine the impact of reputation on price, it is necessary to specify a general model of product price determination. The model used here begins with the standard hedonic approach for differentiated products developed by Rosen (1974). In this model, the equilibrium pxice of a good reflects the value the market assigns to each of the good's characteristics, where this value is determined by the interaction of consumer bid and firm offer functions. For the case considered here, the equilibrium price is specified to be a function of the following four types of characteristics: the current quality of the good, $Q_{t t}$; the good's expected quality, $Q_{i t}^{*}$ which depends on reputation; a vector of average group quality or collective reputation indicators, $\mathrm{R}_{\mathrm{it}}^{\mathrm{i}}$; and, finally, since the product is differentiated, a vector of taste factors, $\mathbf{z}_{i}$. Thus, the equation describing the price of good i in period $t, P_{i t}$, 
takes the form:

$$
P_{i t}=P\left(Q_{i t}, Q_{i t,}^{e}, R_{i t,}^{e}, Z_{i}\right)+\epsilon_{\mathrm{ptt}},
$$

where $\epsilon_{\text {pit }}$ is a mean zero random variable with variance $\sigma_{p}^{2}$. The partial derivative of this function with respect to each characteristic equals the marginal willingness to pay of consumers for that characteristic (Bartik and Smith (1987)).

One of the important attributes of equation (1) is that it distinguishes between the effects on price of current and expected quality. Expected quality, $Q_{i t}^{e}$, should have no effect on price if consumers already know actual quality, $Q_{i t}$, since, in this case, expected quality does not provide any useful additional information. In contrast, if information on current quality is not available, or is very costly to obtain, $Q_{\text {tt }}$ will not enter the consumer decision making process and so cannot affect price. In this case, price will depend only on expected quality and, therefore, on the reputation factors that determine expected quality. Since it includes both $Q_{1 t}$ and $Q_{ \pm t}^{e}$, equation (1) is general enough to allow the data to indicate the extent to which prices are determined by current quality or expected quality and, thereby, does not impose one particular information specification.

The inclusion of the collective reputation indicators $\left(R_{\text {it }}^{c}\right)$ directly in the price equation allows for the possibility that these indicators may reflect a product characteristic which is valued by consumers independently of its usefulness in predicting quality. This type of effect might occur, for example, if there is "snob appeal" associated with a product from a particular 
region, classification or with a particular type of name. If consumers use collective reputation indicators only to predict firm quality, these inaicators will not have a direct impact on price and the coefficients associated with the elements of $R_{i t}^{c}$ will be insignificant in the estimated price equation.

In order to estimate the price equation, equation (1), the factors determining expected quality must be specified. Klein and Leffler (1981) and Shapiro (1983) propose that consumers form expectations of the quality of a firm's product based on the firm's reputation for quality when current quality is costly to observe. Reputation, in turn, depends on the quality of the firm's past output. Tirole (1996) suggests that the expected quality of a firm's output may depend on collective reputation, that is, on indicators of the average quality of the goods produced by a group of firms with which the individual firm is identified. Consumers may use collective reputation indicators if information on individual firm reputation is costly to obtain, or if the use of these indicators can lead to improved forecasts of current quality even when lagged firm quality information is available. Taking both types of reputation into account, expected quality, $Q_{i t}^{e}$, is defined as the predicted value from the quality forecasting equation:

$$
Q_{i t}=Q\left(R_{i t}, R_{i t}^{c}\right)+\epsilon_{\text {Qit }} \text {. }
$$

where $R_{i t}$ is a vector of variables reflecting an individual firm's reputation for quality, based on the quality of its past output, and $\epsilon_{\text {Qit }}$ is a mean zero random variable with variance $\sigma_{Q}^{2}$. The estimated coefficients associated with $R_{i t}$ and $R_{i t}^{c}$ in equation (2) 
will indicate whether information on individual firm reputation or collective reputation (or both) can be used to predict wine quality .

If current quality information is costly to acquire, the reputation indicators, $\mathbf{R}_{\text {it }}$ and $\mathbf{R}_{i t}^{*}$, working through the expected quality variable in the price equation, could be important determinants of price. The magnitude of the impact of reputation on price will depend on both the ability of reputation to predict quality (the size of the coefficients on the reputation indicators in the quality equation, equation (2)) as well as on the value the market places on this quality prediction (the size of the coefficient on expected quality in the price equation, equation (1)).

\section{The Data and Empirical Specification}

The relationship between price, quality, and expected quality, where the latter depends on individual firm reputation and collective reputation, can be quantified by jointly estimating the price equation, equation (1), and the quality equation, equation (2). Estimation of these two equations requires data on individual product prices $\left(P_{1 t}\right)$, quality $\left(Q_{i t}\right)$, individual firm reputation $\left(R_{i t}\right)$, collective reputation $\left(R_{i t}^{c}\right)$, and the other characteristics $\left(z_{i}\right)$ that may affect the price of the product. The empirical analysis below employs data from the market for Bordeaux red wine since this market has several desirable features that make it particularly appropriate for an analysis of the relationship between price, quality, and 
reputation. For example, as noted in the introduction, Bordeaux wine has not changed significantly over time and is differentiated in only a small number of dimensions. This facilitates the measurement of the variables that enter the model described in the previous section. As well, the Bordeaux wine market is comprised of many consumers and many firms, none of which is dominant. Furthermore, in contrast to many other products, quality ratings and data on prices and other characteristics are available for a large sample of Bordeaux wines.

Data on the price, $P$, and quality, Q, of individual Bordeaux wines, where $P$ and $Q$ are the empirical counterparts of $P_{1 t}$ and $Q_{t t}$, are taken from the annual "Bordeaux" issue of the wine spectator, the world's largest circulation wine magazine, and from the wine Spectator's buying guide (Shanken 1993) .5 The key advantages of the wine spectator data (relative to other rankings) are that it includes a large number of different wines, utilizes a finely gradated quality index, provides prices and contemporaneous quality ratings for each wine, and reflects the results of tastings which take place at the same time each year.

The data consist of observations on 151 wines from each of the 1989 and 1990 vintages, 302 observations in all." These two vintages were chosen because they are similar in terms of average price and quality and, as a result, the estimated price and quality equations are less likely to exhibit parameter instability. The price used is the per bottle U.s. retail price provided by Wine Spectator in its "Bordeaux" issue (converted to 
constant 1985 dollars).7

The quality rating system used by wine spectator grades wines from 50 (worst) to 100 (best). Quality is assessed in blind tastings which take into account factors such as a wine's color, aroma, flavor, balance, complexity, and aging potential." While some wine experts claim that rating wine is an intrinsically subjective process, Robert Parker, the developer of the "100 point" rating system, axgues that "wine is no different from any consumer product. There are specific standards of quality that full-time wine professionals recognize." (Robinson $1994, \mathrm{pp} .706-707.)^{9}$

Individual firm reputation, $R_{1 t}$, is assumed to be a function of the quality of the firm's past output and depends on both short-term and long-term factors. The short term reputation of a wine is represented by its quality ratings in the previous two years divided by wine Spectator's overall quality rating for the corresponding vintage $\left(\boldsymbol{Q}_{-1} / \mathrm{v}_{-1}, \boldsymbol{Q}_{-2} / \mathbf{v}_{-2}\right)$. Since the vintage rating is the same for all the wines of a particular vintage year, dividing by vintage quality normalizes for differences across vintages.

As a long time series of Wine Spectator quality ratings is not available, the longex term reputation of each wine is based on a classification of Bordeaux wine producers by Robert Parkex (1991). Parker allocates wines to one of five groups based on their quality performance between 1961 and 1990. Membership of individual wines in these groups is represented by five zero-one dummy variables, R1, R2, R3, R4, and R5, from best to worst, with 
the base case being those wines which are not of sufficient quality to belong to any of these five groups.

In the Bordeaux wine industry, the most important collective reputation indicators are the government-determined regional designations (appellations) 10 and industry-determined "quality" classifications. Whether a wine is included in a particular designation or classification is generally indicated on the wine's label and so is information easily available to consumers. A zero-one dummy variable is used to represent each of the following ten regional designations: Fronsac and others (FRoNsAC), Graves (GRAVES), Haut-Médoc (maUmadoc), Listrac and Moulis (LISTraC), Margaux (Margaux), Pauillac (PAuILLAC), Pomerol (POMEROL), St.-Emilion (STEMILION), St.-Estèphe (STESTEPHE) and St.-Julien (STJULIEN), with the remainder of the wines in the data set being from the rest of the Medoc. Significant coefficients associated with these dumy variables in the quality equation would indicate that they are useful predictors of differences in the quality of the wines from these regions relative to Médoc wines.

Zero-one dumny variables are also used to represent the different gradations in four industry-determined "quality" classifications. The most well-known of these is the 1855 classification. Individual wines ranked in this classification belong to one of five groups (from "best" to "worst"): FirstGrowth (FIRST), Second-Growth (SECOND), Third-Growth (THIRD), Fourth-Growth (FOURTH), and Fifth-Growth (FIFTH). Dummy variables were also used to represent those St.-Emilion wines 
that have been classified as either St.-Emilion Premier Grand Cru Classé (SEPGCC) or St.-Emilion Grand Cru Classé (skgCC) ${ }^{11}$ as well as the Graves wines that have been classified as Graves Cru Classe (GRACC). Finally, three additional dumy variables are used to represent those Bordeaux wines which have been classified as Cru Grand Bourgeois Exceptionnel (CGBE), Cru Grand Bourgeois (CGB) or Cru Bourgeois (CB). ${ }^{12}$ wines which do not belong to any of these classifications form the base case in the estimating equation.

The final two collective reputation indicators that consumers may use to categorize wines are associated with the production of "second" wines. In Bordeaux, firms often produce a "second" wine using grapes which are not good enough for their "first" wine, such as grapes from younger vines. Robinson (1994, p. 861) and Parker (1991, p. 32) argue that this has resulted in a more rigorous selection of grapes and higher quality first wines. ${ }^{13}$ The dummy variable PRODUCESEC is included in the quality equation to indicate that a wine is the first wine produced by a firm that also produces a second wine. This allows for the possibility that first wines may be superior in quality to otherwise identical wines. The dummy variable sacwINE indicates that a wine is a second wine. It is included in the quality equation to determine if, ceteris paribus, second wines differ systematically in quality from other wines.

Parker (1991, p. 33) argues that the wine trade has, often misleadingly, promoted second wines as being as good as first wines, but cheaper. If consumers believe this promotion, the 
prices of second wines should differ, holding everything else constant, from the prices of wines produced by firms with only a single grade of wine. By including the collective reputation variables SECWINE and PRODUCESEC directly in the price equation, it is possible to determine whether the production of a second wine affects the price of either a firm's first wine or its second wine independently of the impact the production of this second wine may have on expected quality.

The price equation specified in section 2 above also includes a vector of characteristics $\left(z_{i}\right)$ which reflect variations in taste across the differentiated product. Since the types of grapes used in a wine have a major impact on its taste and style, grape type may be an important determinant of price. As a result, the estimated price equation includes the percentages used by each producer of four of the five grape varieties that are allowed by Bordeaux production regulations (Cabernet Sauvignon [CABSAUV], Cabernet Franc [CABFRANC], Malbec [MALBEC] and petit Verdot [VERDOT]). ${ }^{14}$ As the grape varieties chosen by a grower depend largely on soil type, the inclusion of grape varieties data in the price equation also controls for differences in land characteristics which could affect the style and taste of the wine produced.

The data set includes data from both the 1989 and 1990 vintages and, as a consequence, a dummy variable for 1990 (D1990) is included in both the price and quality equations. This variable is intended to capture the influence of factors that differ across the two vintages such as consumer incomes and the 
price of substitutes.

\section{Empirical Methodology}

Equations (1) and (2) specify the types of explanatory variables that should appear in the price and quality equations, but do not restrict the functional form of these equations. Five types of linear-in-parameters functional forms were considered for each equation: linear, semi-log, $\log -1$ inear, ${ }^{15}$ reciprocal and reciprocal square root. The evidence given in Appendix $\mathrm{C}$ shows that the linear form provides a reasonable description of the data for the quality equation while the reciprocal square root model is the most appropriate specification for the price equation. The estimates reported below employ these two functional forms.

As noted in section 2 above, the expected quality variable that enters the price equation, equation (1), is the predicted value from the quality forecasting equation, equation (2). To obtain asymptotically efficient estimates of the parameters and correct estimates of the standard errors, the estimation technique used must take account of the presence of this generated regressor in the price equation. ${ }^{16}$ This is done by estimating the two equations of the model jointly using the methodology described in Proposition 3.5 of Pagan (1986, p. 528). ${ }^{17}$ Iteration of this procedure maximizes the concentrated likelihood function: ${ }^{18}$

$$
\log L=\text { constant }-(n / 2) \log |\Sigma|,
$$

where $\Sigma$ is the variance-covariance matrix of the two equations, 
and $\mathrm{n}$ is the number of observations. ${ }^{19}$ The vaxiance-covariance matrix of the estimated parameters is given by:

$$
\frac{2 n}{2 n-k}\left[\sum_{t=1}^{n} \Omega_{t} \Sigma^{-1} \Omega_{t}^{\prime}\right]^{m !}
$$

where $k$ is the total number of parameters in the two equations, $\Omega_{\mathrm{t}}$ is a $\mathrm{k} \times 2$ matrix of the partial derivatives of the price and quality equations with respect to each of the $k$ parameters, and both $\Omega_{t}$ and $\Sigma$ are evaluated at the maximum-likelihood parameter estimates. 20

\section{Estimation Reaulta}

Estimates of the Price and Quality Equations

Estimates of the parameters of the price and quality equations are presented in Table $1 .{ }^{21}$ for the quality equation, six of the seven individual firm reputation indicators are significant at a $95 \%$ confidence level (the seventh is significant at $90 \%)$, seven of the 11 "quality" classification variables are significant relative to the base case wine (an unclassified Médoc), as are seven of the ten governmentdetermined regional classification variables. These results suggest that both individual and collective reputation indicator variables are important signals of differences in current product quality across wines.

The estimated coefficients associated with the quality and expected quality variables in the price equation are both significant and their signs imply that both variables have a positive impact on price. However, the coefficient on expected 
quality, $Q^{e}$, is over 17 times larger than that on current quality, indicating a much greatex role for expected quality than actual quality in price determination. This suggests that consumers rely heavily on reputation when making consumption choices.

significant coeficients associated with the collective reputation variables in the price equation would imply that these variables have an impact on price that is independent of their ability to predict quality. This would occur if, for example, "snob appeal" caused consumers to have a non-quality related preference for a good with a particular name, region of origin or classification. The hypothesis that the eleven industrydetermined classification variables do not enter the price equation directly cannot be rejected using a $95 \%$ confidence interval. ${ }^{22}$ This result indicates that the industry-created classifications are valued by consumers only as signals of product quality and, therefore, yield a benefit to wine producers only to the extent that they provide consumers with quality information.

A similar test indicates, in contrast, that the governmentdesignated regional variables have a statistically significant joint impact on price which is independent of their impact on expected quality. ${ }^{23}$ While none of the individual coefficients on the regional variables is significant at the $95 \%$ level, the coefficients associated with the Graves, Pauillac, and st. Estèphe variables are significant at either 90 or $85 \%{ }^{24}$ The estimated coefficients associated with these three regional dumm 
variables indicate that wines from these regions obtain a lower price than an othexwise equivalent (from a quality and reputation perspective) Médoc wine. 25

As noted above, it has been suggested that the production of a "second" wine may have both price and quality implications. The results in the first column of Table 1 indicate that the qualities of both first and second wines are insignificantly different from wines produced by firms that make only one wine (the coefficients on SECWINE and RRODUCESEC in the quality equation are both.insignificant). As well, the insignificant coefficients on both SECWINE and PRODUCESEC in the price equation indicate that consumers will not pay a premium for a wine just because it is a first or second wine. ${ }^{26}$

The Quantitative Impact of Quality, Expected Quality, and Reputation on Price

In order to provide some perspective on the size of the coefficients in Table 1 , Table 2 presents the estimated marginal impact on price, in dollar terms, of each variable in the quality and price equations. The first column of figures in Table 2 gives the dollar change in price due to a one unit increase in each variable that enters the quality equation for the impact of each dummy variable relative to the base case). The magnitude of this effect depends both on the ability of the variable in question to forecast quality as well as on the impact of expected quality on price. The second column of dollar values in Table 2 represents the marginal impact on price of the variables which 
enter the price equation directly. ${ }^{27}$

The results presented in Table 2 make clear the large relative importance of reputation effects in price determination. A one unit increase in expected quality raises the price per bottle by $\$ 4.91$, an amount equal to 17 percent of the price of the average bottle of wine in the data set $(\$ 29.51)$. In contrast, a one unit increase in actual quality raises the price per bottle by only $\$ .24$, an increase which is one twentieth as large. Furthermore, while both short-term and long-term individual firm reputation variables have a significant impact on quality, the impact on price of the long-term reputation variables is far greater in magnitude. For example, a one unit increase in last period's quality $\left(Q_{-1}\right)$ increases the current pxice by only \$.11. However, a wine with a quality rating of $\mathbf{R 5}$, based on its performance from 1961 to 1990, will earn, on average, $\$ 2.89$ more than the base case wine. Similarly, wines rated from $R 4$ to $R 1$ achieve premia of from $\$ 4.45$ to $\$ 20.40$. since a ten point change in quality would be relatively large, the long-term reputation effects are quantitatively much more important than the short-term reputation effects in price determination. These results suggest that consumers axe willing to pay considerably more for a wine with a long quality track record and that they do not view a recent change in quality to be as valuable an indicator of a product's current quality.

The variables that act as signals of collective reputation are also shown in Table 2 to have a large quantitative impact on price. For example, a wine classified in 1855 as a First-Growth 
earns, on average, approximately $\$ 14$ more than the base case wine, while a wine classified as Second-Growth to Fifth-Growth earns approximately $\$ 4$ more than an unclassified wine. ${ }^{28}$ Two of the other six classification variables also have large and significant effects on price as do seven of the ten regional variables.

The evidence presented in Table 2 confirms that consumers are willing to pay a significant premium for wines with certain collective reputation signals and that, therefore, they value these variables as predictors of individual wine quality. Given the large number of Bordeaux wine producers, it is not surprising that consumers use signals of product quality other than individual firm reputation to predict current quality and that these collective reputation indicators have an important impact on price.

Some Indicators of the Robustness of the Estimates

A number of tests were carried out to assess the robustness of the estimates. The appropriateness of the functional form used for the estimated price equation could not be rejected at a $95 \%$ significance level using a test very similax to that of the standard RESET test. ${ }^{29}$ Following Breusch and Pagan (1979), the price and quality equations were also examined for the presence of heteroscedasticity. The test results indicate that the hypothesis of homoscedasticity cannot be rejected at the $95 \%$ level for the quality equation and cannot be rejected at the $99 \div$ level for the price equation. ${ }^{30}$ While this test uses a single 
equation technique, it provides some indication that heteroscedasticity is not a serious problem.

The joint non-linear estimation of the quality and price equations assumes that the parameters in the quality equation are the same as the parameters that determinine expected quality in the price equation. A test of these cross equation restrictions indicates that the joint restrictions could not be rejected at a 95 confidence level. ${ }^{31}$ This suggests that the expectations formation mechanism used is not inconsistent with the data.

Although the insignificance of the coefficient associated with D1990 suggests that aggregation across time is not inappropriate, the restrictions implied by combining data from the 1989 and 1990 vintages were tested using a likelihood ratio test for the equality of all the parameters across the two years. This test could not reject the parameter constancy restrictions and, thus, suggests that aggregating the data for these two years did not bias the estimates. ${ }^{32}$

During estimation the predicted values of the price variable were not restricted to be positive (even though only a positive price is reasonable), nor were the predicted values of the quality variable restricted to be between 50 and 100 (the allowable range of values on the "100 point" scale). Although these restrictions were not imposed, the estimated predicted values of both the price and quality variables were within the allowable ranges for every observation in the data set.

The $\mathrm{R}^{2}$ statistic in the price equation is .877 while, in the quality equation, it is .464 . Given that the analysis uses cross 
section data, the proportion of the variance in quality explained by the estimated model is of reasonable size while the explained proportion of the price variance is quite large. ${ }^{33}$

\section{Concluding Comments}

The analysis above adas to the small literature which examines the empirical importance of reputation effects. The results indicate that the price of the differentiated product examined, Bordeaux wine, depends significantly on both expected quality (reputation) and current quality. However, the marginal impact of expected quality on price is approximately twenty times greater than that of current quality. This result is consistent with a world in which consumers have incomplete information on product quality, perhaps due to the costs of information gathering, Given this incomplete quality information, consumers rely heavily on both individual firm reputation -- based on the past quality of the firm's output - and collective (or group) reputation indicators - characteristics which allow consumers to segment firms into groups with differing average qualities -- to predict current product quality, as in the theoretical models of individual firm reputation proposed by klein and Lefflex (1981), Shapiro (1983) and Allen (1984), and the collective reputation model of Tirole (1996).

The empirical evidence further indicates that consumers consider a long-term reputation for quality to be a better signal of current quality than more recent quality movements. This implies that it may take considerable time for a firm to 
establish a reputation for quality that would yield a significant price premium.

The results also show that collective reputation indicators play a significant role in price determination principally through their impact on expected quality. While some of the government-determined regional designations (appellations) have a weak direct effect on price, this effect is dominated by the role of these collective reputation variables as quality predictors. The industry-determined "quality" classification variables, such as the well-known 1855 classification, are only significant determinants of price to the extent that they are good predictors of quality. Since they do not have an independent effect on price, they are useful to firms only to the extent that they reflect quality differences.

Akerlof (1970) shows that in a market where consumers lack information on product quality, a firm cannot charge a premium for a high quality product and, thus, in equilibxium only low quality products ("lemons") are traded. The existence of quality classifications and other collective reputation indicators that are good predictors of quality, and which consumers use and value, may help higher quality firms differentiate their product from the output of other firms. As a result, collective reputation indicators may be of practical importance to firms and may lead to the production of a wider quality range of goods. While the empirical evidence indicates that reputation effects are large in magnitude, current quality also has a significant, although small, impact on price. One explanation 
for why both current quality and reputation are significant determinants of price may be that there are different types of agents in the market, some of whom are better informed about. current quality than others. ${ }^{34}$ Alternatively, consumers may view observable quality ratings as noisy indicators of actual quality, so they may rely to a greater extent on the accumulated evidence embodied in reputation. ${ }^{35}$ The significance of both current and expected quality in the price equation indicates that it is important to not restrict the model to one particular information specification.

The analysis described above suggests a number of avenues for future research. Estimates derived using alternative price and quality data for wine, as well as for other products, would provide evidence of the robustness of the results. It may also be possible to examine dynamic (learning) effects by using a time series of price data. A further topic for future research is to determine whether there is a systematic difference between the impact of collective reputation signals that are industrypromoted (such as the quality classifications used above), firmchosen (such as whether the firm produces a second wine), government regulated (such as the regional classifications), or exogenous (such as the nationality of a producer).

One of the more puzzling aspects of the results presented above is the finding that the "quality" classification schemes are such useful predictors of quality. The expectation of the periodic re-evaluation of Crus Bourgeois and St. Emilion wines could provide a possible enforcement mechanism for the wines that 
fall into these categories. However, the 1855 classification, empirically a very successful predictor of quality, has never been updated, with the exception of the 1973 elevation of MoutonRothschild from Second-Growth to First-Growth status. A classification system with no quality control mechanism would be expected to create an incentive for firms to "free ride" on the quality reputation of the group. However, after 140 years, the premia accorded wines that were classified in 1855 does not seem to have been dissipated by free-riding. The longevity of the value of this classification suggests that firms have found a mechanism to successfully enforce quality standards among the group's members. More research is needed to expand our understanding of this method of group quality enforcement. 


\section{References}

Abel, Andrew, and Frederic Mishkin. 1983. An integrated view of tests of rationality, market efficiency and the short-run neutrality of monetary policy. Journal of Monetary Economics 11:324.

Akexlof, George A. 1970. The market for "lemons": quality uncertainty and the market mechanism. Quarterly Journal of EConomics $84: 488-500$.

Allen, Franklin. 1984. Reputation and product quality. Rand Journal of Economics $15: 311-327$.

Bartik, Timothy J., and V. Kerry Smith. 1987. Urban amenities and public policy. In Handbook of regional and urban economics, Volume 2, edited by Edwin S. Mills. Amsterdam: North-Holland, pp. 12071254.

Berger, Dan. 1994. Sauvignon blanc sales a disaster. Los Angeles Times reprinted in The Edmonton Journal, October $12: \mathrm{D} 8$. Borenstein, Severin, and Martin B. Zimmerman. 1988. Market incentives for safe commercial airline operation. American Economic Review $78: 913-35$.

Breusch, Trevor S., and Adrian R. Pagan. 1979. A simple test for heteroscedasticity and random coefficient variation. Econometrica $47: 1287-94$

Caves, Richard E., and David P. Greene. 1996. Brands' quality levels, prices, and advertising outlays: empirical evidence on signals and information costs. International Journal of Industrial Organization $14: 29-52$. Combris, Riexre, Sébastien Lecocq, and Michael Visser. 1997. 
Estimation of a hedonic price equation for Bordeaux wine: Does quality matter? Economic Journal 107:390-402.

Cooper, Russel1, and Thomas W. Ross. 1984. Prices, product

qualities and asymmetric information: the competitive case. Review of Economic Studies 51:197-207.

Davidson, Russel1, and James G. Mackinnon. 1993. Estimation and inference in econonetrics. New York: Oxford University Press. Di Vittorio, Albert, and Victor Ginsburgh. 1994. Red wines of Médoc: vintages from 1949 to 1989 at Christie's auctions. Unpublished paper.

Geistfeld, Loren V. 1988. The price quality relationship: the evidence we have, the evidence we need. In The frontier of research in the consumer interest edited by E.S. Maynes and the ACCI Research Committee. Columbia, Mo: American Council on Consumer Interests, pp. $143-72$.

Ginsburgh, Victor, Muriel Monzak, and Andras Monzak. 1992. Red wines of Médoc: what is wine tasting worth? Unpublished paper. Gorton, Gary. 1996. Reputation formation in early bank note markets. Journal of Political Economy 104:46-97.

Hoffman, Dennis L., stuart A. Low, and Don E. Schlagenhauf. 1984. Tests of rationality, neutrality and market efficiency. Journal of Monetary Economics $14: 339-63$.

Jarrel1, Gregg, and Sam Peltzman. 1985. The impact of product recalls on the wealth of sellers. Joumal of Political Economy $93: 512-536$

Karpoff, Jonathan M., and John R. Lott. 1993. The reputational penalty firms bear from committing criminal fraud. Journal of Law 
and EConomics 36:757-802.

Klein, Benjamin, and Keith B. Leffler. 1981. The role of market forces in assuring contractual performance. Journal of Political Economy $89: 615-641$.

Kramer, Matt. 1994. Pinot Gris: California's next big white. Wine Spectator September 30, 19:24.

Landon, Stuart, and C.E. Smith. 1997. The use of quality and reputation indicators by consumers: the case of Bordeaux wine. Journal of Consumer Policy. In press.

Mackinnon, James G., H. White, and R. Davidson. 1983. Tests for model specification in the presence of alternative hypotheses: some further results. Journal of Econometrics 21:53-70. Mishkin, Frederic. 1982. Does anticipated monetary policy matter? An economic investigation," Joumal of political Economy 90:22-51. Molyneux-Berry, David. 1990. The Sotheby's guide to classic wines and their labels. New York: Ballantine Books.

Nerlove, Marc. 1995 Hedonic price functions and the measurement of preferences: the case of Swedish wine consumers. European Economic Review $39: 1697-1716$.

Oxley, Les, and Michael McAleer. 1993. Econometric issues in macroeconomic models with generated regressors. Journal of Economic Surveys $7: 1-40$.

Pagan, Adrian. 1984. Econometric issues in the analysis of regressions with generated regressors. International Economic Review 25:221-47.

Pagan, Adrian. 1986. Two stage and related estimators and their applications. The Review of Economic Studies 53:517-38. 
Parker, Robert M. 1991. Bordeaux. New York: Simon \& Schuster. Robinson, Jancis. 1994. The Oxford companion to wine. Oxford: Oxford University Press.

Rosen, Sherwin. 1974. Hedonic prices and implicit markets: product differentiation in pure competition. Journal of Political Economy $82: 34-55$.

Shanken, Marvin, editor. 1993. The Wine Spectator's ultimate guide to buying wine 1994 edition. New York: Wine Spectator Press. Shapiro, Carl. 1983. Premiums for high quality products as returns to reputations. Quarterly Journal of Economics 98:659-679. Tirole, Jean. 1996. A theory of collective reputations (with applications to the persistence of corruption and to firm quality). Review of Economic Studies $63: 1-22$.

Zeithaml, Valerie A. 1988. Consumer perceptions of price, quality and value: A means-end model and synthesis of evidence. Journal of Marketing $53: 2-22$. 


\section{Endnotes}

1. A large literature investigates the correlation between quality and price, but it does not incorporate reputation effects. See the surveys by Zeithaml (1988) and Geistfeld (1988) .

2. Recent papers by Nerlove (1995) and Combris, Lecocq, and Visser (1997) also use data from the market for wine, but do not examine reputation effects. Landon and Smith (1997) use wine data to analyze reputation effects, but do not directly measure the relative importance of reputation and current quality in price determination, nor can their estimates distinguish whether reputation signals affect price directly or only indirectly through expected quality. Di vittorio and Ginsburgh (1994) and Ginsburgh, Monzak, and Monzak (1992) also use wine data, but do not explicitly model expected quality (reputation).

3. Jarrell and Peltzman (1985) and Borenstein and zimmerman (1988) examine empirically issues which are very similar to collective reputation. Jarrell and Peltzman (1985) find that a recall by one U.S. automobile or drug firm has an "externality effect" in that it reduces its U.S. competitors' share value. In contrast, Borenstein and zimmerman (1988) find that the demand faced by one airline is not affected when another airline has an accident.

4. Government regulations restrict many of the characteristics of Bordeaux winemaking, including, for example, the region where the grapes are grown, grape varieties used, growing methods, maximum allowable yields, the alcoholic strength of the wine, and 
the type of bottles used.

5. Precise definitions of all variables that enter the estimating equations are given in Appendix $A$. The "in and " $t$ " subscripts have been dropped for convenience where possible. Summary statistics for the data are given in Appendix B. 6. Every wine listed in the "Bordeaux" issue for which a price is reported and for which two previous annual wine spectator tastings are available is included in the data set. The wines of many firms are included fox both years, but this is not the case for all the firms in the data set.

7. Wine spectator calculates prices by surveying a vaxiety of retail price sources. Actual prices could differ from these prices. Note that, although their data set does not include wine, Caves and Green (1996) obtain very similar results when they use list prices rather than actual transaction prices. 8. As is the case with many consumer goods, Bordeaux wine is often not consumed at the time of purchase. However, even if consumers intend to let a wine age, they must base their purchase decisions on the quality information currently available.

9. Quality can be treated as predetermined with respect to price because most of the factors that affect wine quality are exogenous (e.g., weather) or are determined by decisions made by producers years before a wine is released. For example, the producer must decide what types of grapes to grow, the amount of pruning, when to pick the grapes, the type of fermentation tanks to use, the length of time to age the wine in barrels, the quality of the barrels, and when to release the wine. 
10. These regional designations follow the Appellation d'Origine Contrôlée $(A O C)$ system which requires growers to meet certain quality standards such as the use of certain growing methods and approval of the wine by a tasting panel. While these regulations are presumably intended to directly maintain wine quality, Molyneux-Berry $(1990$, p. 11) argues that enforcement of all the $A O C$ regulations is for all practical purposes not possible and "The guarantee of quality today still remains, as it has always done in the past, on the reputations of the grower and the wine merchant involved."

11. The classification of St.-Emilion wines was first undertaken in 1955. This classification was updated in 1959, 1969, and 1985. 12. The Cru Bourgeois classification was first used in 1932. This classification was updated in 1966 and 1978. 13. It is also possible that, by producing a second wine, firms have not changed their grape selection procedure, but have simply chosen to market wine made from lower quality grapes rather than sell these grapes to producers of generic Bordeaux wine. 14. The percentage of Merlot used by producers forms the base case and so is not included in the estimating equation. 15. In the log-linear specification, only those explanatory variables which are always strictly positive were transformed. 16. Some of the difficulties associated with estimating generated regressor models are discussed in Pagan $(1984,1986)$ and Oxley and McAleer (1993).

17. This involves the following procedure. The quality equation is estimated and then the price equation is estimated with the 
predicted value from the quality equation substituted for the expected quality variable in the price equation. Using these parameter estimates, the estimated residuals are calculated for both the quality and price equations. The derivatives of each equation with respect to all the parameters in the model are then calculated for every observation in the data set and the residuals and derivatives for the two equations are stacked. Finally, a weighted regression of the stacked residuals on the stacked derivatives is undertaken and the estimated parameters from this regression are used to update the initial parameter estimates.

18. While iteration is not necessary to obtain asymptotically efficient estimates, it does ensure that the likelihood function is maximized. Convergence took less than 10 iterations in all cases. Convergence was deemed to have occurred if the value of the likelihood function changed by less than .00125 percent between iterations and the largest gradient associated with any of the parameters was equal to zero in its fourth decimal place. 19. In order to identify the parameters associated with $Q$ and $Q^{\circ}$ in the price equation, it is necessary to restrict $\Sigma$ to be diagonal. That there is no contemporaneous correlation across equations is a standard assumption when contemporaneous actual and expected values from a forecasting equation are incorporated in a second equation (See Mishkin 1982; Abel and Mishkin 1983; and Hoffman, Low, and Schlagenhauf 1984). Both Abel and Mishkin (1983) and Hoffman, Low, and Schlagenhauf (1984) provide evidence that suggests that imposing this restriction will not affect the 
results significantly even if the restriction is not true. 20. This form of the variance-covariance matxix follows pagan (1986, p. 528) and Davidson and Mackinnon (1993, p. 319). 21. Since the dependent variable in the reciprocal square root functional form of the price equation is $\left(P_{1 t}\right)^{* .5}$, a negative coefficient associated with an explanatory variable implies a positive effect on price.

22. The likelihood ratio test statistic, distributed as a $\chi^{2}$, is 8.44. The 95 critical value with 11 degrees of freedom is 19.68. The hypothesis that the coefficients on the five dumm variables associated with the 1855 classification are zero, while restricting the coefficients on the other classification dumy variables in the price equation to be zero, could also not be rejected. For this case, the test statistic is 5.94 and the $95 \%$ critical value is 11.07 with 5 degrees of freedom. 23. The hypothesis that the government-designated regional appellation variables do not have a direct effect on price (in addition to their effect through expected quality) is rejected at the 95 confidence level. The likelihood ratio test statistic is 35.78 . The 95 critical value for a $\chi^{2}$ test statistic with 10 degrees of freedom is 18.31. The appellation variables should not reflect differences in wine styles across regions since these differences should be captured by the grape variety variables. 24. A test of the hypothesis that the coefficients on all the regional variables in the price equation are zero, except those associated with these three variables, yields a likelihood ratio test statistic of 14.43 . With seven degrees of freedom, the $95 \%$ 
$\chi^{2}$ critical value is 14.07 while the 99 critical value is 18.48 .

25. A possible explanation for this result is that the names of these three appellations may not be attractive to consumers in the U.S. market. A non-French-speaking consumer could find "Graves" to be an unappealing name (in French "graves" means "gravelly terrain") and "Pauillac" and "St. Estèphe" more difficult to pronounce than the other appellation names. Berger (1994) argues that the price of a Sauvignon Blanc wine is typically lower than a comparable Chardonnay because "Chardonnay is easier to pronounce than Sauvignon Blanc". Kramer (1994) predicts that a wine with "a pronounceable French name" will be more successful in the U.S. market. Thus, rather than acting only as a signal of quality, the appellation names themselves may be viewed as a characteristic which yields positive or negative value to consumers.

26. One reason why these variables do not have a significant impact on price may be that the average consumer is unaware that a wine is a first or second wine since this information is typically not included on a wine's label.

27. The marginal dollar effect on price of variable $x_{i}$ is calculated as:

$$
\Delta \mathrm{P}=\left(\overline{\mathrm{I}}+\beta_{1}\right)^{-2}-\bar{\Pi}^{-2},
$$

where $\beta_{i}$ is the estimated coefficient associated with variable $\mathrm{X}_{i}$, II is the dependent variable $\left(\mathrm{P}^{-1 / 2}\right), \mathrm{P}$ is the price, and $\overline{\mathrm{II}}$ is 
the mean of $I I$ when $x_{i}$ is a continuous variable and the mean of $I I$ for the observations associated with the relevant base case when $x_{i}$ is a dumy variable (the observations for which the dummy variable equals zero).

28. Di Vittorio and Ginsburgh (1994) and Ginsburgh, Monzak, and Monzak (1992) also find the 1855 classification to be an important determinant of wine prices. However, their estimates do not reveal whether the 1855 classification is a predictor of wine quality.

Given the estimated standard errors in Table 1, the SecondGrowth to Fifth-Growth wines all attain the same quality premium using a 95 percent confidence level. This finding is inconsistent with a declining quality scale, which the 1855 classification was intended to be. However, except for FixstGrowth wines, wine labels generally only indicate that a wine was classified in 1855, not its level of classification. As a consequence, wine purchasers do not have easily-available information that they can use to differentiate Second-Growth to Fifth-Growth wines.

29. This test involved using the estimated maximum-likelihood parameters to form the predicted value of the dependent variable in the price equation. This predicted value was squared and this squared value added to the price equation as an additional explanatory variable. The model was estimated exactly as before and iterated until the gradients were zero. The asymptotic tstatistic on the square of the dependent variable in the price equation was 1.32 . 
30. The heteroscedasticity test was undertaken by regressing the squared errors from each equation on the explanatory variables that enter each equation (either directly or indirectly) using a simple linear specification. The quality equation regression included 31 regressors in addition to a constant while the price equation included 36. The LM test statistics are 33.15 for the quality equation and 52.64 for the price equation. The $95 \%$ critical value for a $\chi^{2}$ statistic with 31 degrees of freedom, as in the quality equation regression, is 44.97 . The 95 oritical value for a $\chi^{2}$ statistic with 36 degrees of freedom, as in the price equation regression, is 50.96, while the critical value at $99 \div$ is 58.57 .

31. The Iikelihood ratio test statistic was 17.08 . The 95 critical value for the $\chi^{2}$ distribution with 17 degrees of freedom is 27.59 .

32. The calculated test statistic is 49.40 while the $95 \%$ critical value with 50 parameter restrictions is 67.4 . 33. Given the complexity of the estimation procedure, $R^{2}$ is defined here as the ratio of the explained sum of squares to the total sum of squares for each equation.

34. Cooper and Ross (1984) present a model with informed and uninformed consumers.

35. This explanation was suggested by a referee. 
Table 1: Quality and Price Equation - Parameter Estimates

Quality Equation

Dependent Vartable:

\section{Explanatory Variables}

$\mathbf{Q}^{*}$

Q
Price Equation

$$
\text { p.s }
$$

$.0209(7.81)^{* * *}$

$-.0012(3.14)^{* * * *}$

Firm Reputation Indicators:

$$
\begin{aligned}
& \mathbf{Q}_{-1} \mathbf{N}_{+1} \\
& \mathbf{Q}_{\mathbf{1}} \mathbf{N}_{+1}
\end{aligned}
$$$$
\text { R1 }
$$

R2

$\mathbf{R 3}$

R4

R5

Collective Reputation Indicators:

(a) Quality Classtfications

$\begin{array}{ll}\text { FIRST } & 2.336(4.47)^{* * *} \\ \text { SECOND } & .8787(2.59)^{* * *} \\ \text { THIRD } & .8266(2.58)^{* * *} \\ \text { FOURTH } & .7355(1.99)^{* * *} \\ \text { FIFTH } & .8794(2.77)^{* * *} \\ \text { CGBE } & .5515(1.60)^{*} \\ \text { CGB } & .1198(0.38) \\ \text { CB } & .5455(1.58)^{* *} \\ \text { SEPGCC } & 1.211(2.51)^{* * *} \\ \text { SEGCC } & .4129(0.93) \\ \text { GRACC } & 1.500(3.85)^{* * *}\end{array}$

(b) Regional Classifications

$$
\begin{aligned}
& 2.488(1.89)^{* *} \\
& 2.293(1.99)^{* * *} \\
& 4.429(7.36)^{* * *} \\
& 2.919(6.76)^{* * *} \\
& 1.959(6.26)^{* * *} \\
& 1.558(4.73)^{* * *} \\
& 1.081(5.08)^{* * *}
\end{aligned}
$$


LISTRAC

MARGAUX

paumllac

POMEROL

STEMILION

STESTEPHE

STJULIEN

HAUTMEDOC
$1.520(1.05)$

$2.818(2.22)^{* * *}$

$4.674(3.52)^{* * *}$

$5.352(4.05)^{* * *}$

$3.682(2.84)^{* * *}$

$4.678(3.49)^{* * *}$

$4.077(3.05)^{* * *}$

$.5684(0.46)$

. $.1911(0.41)$

Grape Varieties:

CABFranC

CaBsaUy

MALBEC

VERDOT

Other Variables:

D1990
Constant

$\mathbf{R}^{2}$
$.0659(0.16)$

$79.87(40.0)^{* * *}$

.464
$-.0087(0.36)$

$.0036(0.36)$

$-.0004(2.81)^{* * *}$

$-.0066(0.21)$

$.0042(0.14)$

$.0536(1.56)^{*}$

$.0102(0.29)$

$0118(0.38)$

$.0586(1.76)^{* *}$

$.0434(1.32)$

$.0236(0.87)$

., $0002(1.44)$

$-.0002(0.26)$

., $0008(1.40)$

$.0050(0.60)$

$2.193(9.76)^{* * *}$

.877

Note: The number in brackets beside each estimated coefficient is the absolute value of the t-statistic.

*** The estimated coefficient associated with the explanatory variable is significant at 95 percent.

** The estimated coefficient associated with the explanatory variable is significant at 90 percent.

* The estimated coefficient associated with the explanatory variable is significant at 85 percent. 
Table 2: Real Dollar Marginal Effects on Price

Quality Equation

Variables

$Q^{e}$

$\mathbf{Q}$
Price Equation

Variables

$4.91 * * *$

$.24 * * *$

Firm Reputation Indicators

$\begin{array}{lr}\text { Q.1 } & .11^{* *} \\ \mathbf{Q}_{+2} & .12^{* * *} \\ \mathbf{R} 1 & 20.40^{* * *} \\ \mathbf{R 2} & 10.24^{* * *} \\ \text { R3 } & 5.93^{* * *} \\ \text { R4 } & 4.45^{* * *} \\ \text { R5 } & 2.89^{* * *}\end{array}$

Collective Reputation Indicators

(a) Quatity Classifications

$\begin{array}{lc}\text { FIRST } & 13.79^{* * *} \\ \text { SECOND } & 4.02^{* * *} \\ \text { THIRD } & 3.75^{* * *} \\ \text { FOURTH } & 3.29 * * * \\ \text { FIFTH } & 4.02^{* * *} \\ \text { CGBE } & 2.40^{*} \\ \text { CGB } & .49 \\ \text { CB } & 2.37 * \\ \text { SEPGCC } & 5.85^{* * *} \\ \text { SEGCC } & 1.76 \\ \text { GRACC } & 7.60^{* * *}\end{array}$


(b) Regional Classifications

$\begin{array}{llc}\text { FRONSAC } & -.29 & 2.96 \\ \text { GRAVES } & 10.08^{* * *} & -7.14^{* *} \\ \text { LISTRAC } & 2.52 & .64 \\ \text { MARGAUX } & 5.48^{* * *} & -.53 \\ \text { PAUILLAC } & 11.84^{* * *} & -8.07 * \\ \text { POMEROL } & 15.15^{* * *} & -2.45 \\ \text { STEMILION } & 8.04^{* * *} & -1.73 \\ \text { STESTEPHE } & 11.86^{* * *} & -8.60^{* *} \\ \text { STJULIEN } & 9.43^{* * *} & -5.91 \\ \text { HAUTMEDOC } & .85 & 2.02\end{array}$

(c) Second Wine Indicators

$\begin{array}{lcc}\text { SECWINE } & .39 & 1.94 \\ \text { PRODUCESEC } & -.79 & -67\end{array}$

Grape Varieties

$\begin{array}{lc}\text { CABFRANC } & .08^{* * * *} \\ \text { CABSAUV } & .04 \\ \text { MALBEC } & .05 \\ \text { VERDOT } & .17\end{array}$

Year Dummy Variable for 1990

D1990

*** The estimated coefficient associated with the explanatory variable is significant at 95 percent.

** The estimated coefficient associated with the explanatory variable is significant at 90 percent.

* The estimated coefficient associated with the explanatory variable is significant at 85 percent. 


\section{Appendix A: Variable Definitions and Data Sources} CABFRANC - a wine producer's average percentage of the cabernet Franc grape variety. Source: Parkex (1991) except for a small number of wines which were not included in Parker for which data from Molyneux-Berry (1990) were used. Second labels were assumed to have the same grape composition as first labels.

CABSAUV - average percentage of grapes in the wine which are of the Cabernet Sauvignon variety. Source is the same as for CABFRANC.

CB - a dummy variable which equals one if the wine was classified as a Cru Bourgeois in the 1978 Medoc classification and zero otherwise. Source: Parker (1991, p. 930-1).

CGB - a dumy variable which equals one if the wine was classified as a Cru Grand Bourgeois in the 1978 Médoc classification and zero otherwise. Source: Parker (1991, p. $929-30$ ) .

CGBE - a dummy variable which equals one if the wine was classified as a Cru Grand Bourgeois Exceptionnel in the 1978 Médoc classification and zero otherwise. Source: Parker (1991, p. 929).

D1990 - a dummy variable which equals one if the wine is from the 1990 vintage and zero otherwise.

FIFTH - a dummy variable which equals one if the wine was classified as a Fifth-Growth in the classification of 1855 and zero otherwise. Source: Parker (1991, p. 925). FIRST - a dummy variable which equals one if the wine was classified as a First-Growth in the classification of 1855 
and zero otherwise. Source: Parker (1991, p. 924).

FouRTI - a dummy variable which equals one if the wine was classified as a Fouxth-Growth in the classification of 1855 and zero otherwise. Source: Parker (1991, p. 925).

FRONSAC - a dummy variable which equals one if the wine has a Fronsac or "other" appellation and zero otherwise. "Other" includes wine producers from outside the other appellations specified or who combine grapes from more than one appellation and who, therefore, have a Bordeaux designation only. Source is the same as for $Q$.

GRAVES - a dummy variable which equals one if the wine has a Graves appellation and zero otherwise. Source is the same as for $Q$.

GRACC - a dummy variable which equals one if the wine was classified (Cru Classé) in the 1959 Graves classification and zero otherwise. Chateau Haut-Brion was included in the First Growth category and not the Graves Cru classe category. It is the only wine which is recognized in two categories. Source: Parker (1991, p. 926).

EAUTMEDOC - a dummy variable which equals one if the wine has an Haut-Medoc appellation and zero otherwise. Source is the same as for $Q$.

LISTRAC - a dummy variable which equals one if the wine has a Listrac or Moulis appellation and zero otherwise. Source is the same as for $Q$.

MALBEC - average percentage of grapes in the wine which are of the Malbec variety. Source is the same as for CABF. MargauX - a dumny variable which equals one if the wine has a 
Margaux designation and zero otherwise. Source is the same as for $Q$.

P - the price per bottle of wine in 1985 U.S. dollars. The source of the nominal prices is the same as for $Q$. The deflator is the quarterly average of the U.S. CPI in the first quarter of the year in which the wine is released. This price index is reported in the International Monetary Fund's International Financial Statistics. 1994, p.114. PAUILLAC - a dummy variable which equals one if the wine has a Pauillac designation and zero otherwise. Source is the same as for $Q$.

POMEROL - a dumny variable which equals one if the wine has a Pomerol designation and zero otherwise. Source is the same as for $Q$.

PRODUCESEC - a dummy variable which equals one if the wine is the first wine of a producer that also produces a second wine and zero otherwise. Source: Parker (1991) except for a small number of wines which were not included in Parker for which data from Molyneux-Berry (1990) were used.

Q - quality measure. Source: 1989: "Rating 1989 Bordeaux Reds," Wine Spectator, Vol. XVI, No. 21, 15 March 1992, 26-32. 1990: "Rating Bordeaux's Generous '90s," Wine Spectator, Vol, XVII, No.22, 31 March 1993, 30-39.

Q.1 - lagged quality. Source is the same as for $Q$ as well as " 88 Bordeaux Tasting Notes," Wine Spectator, Vol. XVI, No. 2, 30 April 1991 and Shanken (1993).

Q.2 - twice lagged quality. Source is the same as for $Q$ as well as "Tasting the 87 Bordeaux," Wine Spectator, Vol. XV, No. 
3, 15 May 1990, 46-9 and Shanken (1993).

R1 - a dumny variable which equals one if a wine producer is included in Parker's list of "First-Growths" and zero otherwise. Source: Parker (1991, p. 932).

R2 - a dummy variable which equals one if a wine producer is included in Parker's list of "Second-Growths" and zero otherwise. Source: Parker (1991, p. 933).

R3 - a dummy variable which equals one if a wine producex is included in Parker's list of "Third-Growths" and zero otherwise. Source: Parker (1991, p. 933).

R4 - a dummy vaxiable which equals one if a wine producer is included in Parkex's list of "Fourth-Growths" and zero otherwise. Source: Parker (1991, p. 933).

R5 - a dummy variable which equals one if a wine producer is included in Parker's list of "Fifth-Growths" and zero otherwise. Source: Parker (1991, p. 933-4).

SECOND - a dummy variable which equals one if the wine was classified as a second-Growth in the official classification of 1855 and zero otherwise. Source: Parker (1991, p. 924). SECWINE - a dummy variable which equals one if the wine is a second wine and zero otherwise. Source is the same as for PRODUCESEC.

SEGCC - a dummy variable which equals one if the wine was classified as a Grand Cru Classe in the $1985 \mathrm{st}$. Emilion classification and zero otherwise. Source: Parker (1991, p. 928-9) .

sEPGCC - a dummy variable which equals one if the wine was classified as a Premier Grand Cru Classe in the $1985 \mathrm{st}$. 
Emilion classification and zero otherwise. Source: Parker (1991, p. 928)

STramluIoN - a dummy variable which equals one if the wine has a St. Emilion designation and zero otherwise. Source is the same as for $Q$.

STESTEPHE - a dummy variable which equals one if the wine has a St. Estèphe designation and zero otherwise. Source is the same as for $Q$.

STJULIBN - a dummy variable which equals one if the wine has a St. Julien designation and zero otherwise. Source is the same as for $Q$.

THIRD - a dummy variable which equals one if the wine was classified as a Third-Growth in the official classification of 1855 and zero otherwise. Source: Parker (1991, p. 9245).

$v_{-1}$ and $v_{-2}$ - the average quality of the previous vintage and of the vintage two years before, respectively, in Bordeaux. Source: "Rating Bordeaux Vintages 1961-1991," Wine Spectator, Vol. 18, No. 21, 31 March 1994, 35. VERDOT - average percentage of grapes in the wine which are of the petit verdot variety. Source is the same as for CABFRANC. 
Appendix B: Data Summary Statistics

\begin{tabular}{|c|c|c|c|}
\hline & Mean & Minimum & Maximum \\
\hline $\mathbf{Q}$ & 89.82 & 75 & 100 \\
\hline $\mathbf{Q}_{-1}$ & 88.34 & 55 & 100 \\
\hline Q.z & 83.05 & 65 & 100 \\
\hline R1 & $.106(32)$ & 0 & 1 \\
\hline $\mathbf{R 2}$ & $+103(31)$ & 0 & 1 \\
\hline R3 & $.146(44)$ & 0 & 1 \\
\hline $\mathbf{R 4}^{\circ}$ & $.066(20)$ & 0 & 1 \\
\hline R5 & $.235(71)$ & 0 & 1 \\
\hline Not R1-R5 & $.344(104)$ & & \\
\hline FIRST & $.033(10)$ & 0 & 1 \\
\hline SECOND & $.073(22)$ & 0 & 1 \\
\hline THIRD & $.063(19)$ & 0 & 1 \\
\hline FOURTH & $.043(13)$ & 0 & 1 \\
\hline FIFTH & $.079(24)$ & 0 & 1 \\
\hline CGBE & $.066(20)$ & 0 & 1 \\
\hline CGB & $.086(26)$ & 0 & 1 \\
\hline CB & $.043(13)$ & 0 & 1 \\
\hline SEPGCC & $.066(20)$ & 0 & 1 \\
\hline SEGCC & $.076(23)$ & 0 & 1 \\
\hline GRACC & $.073(22)$ & 0 & 1 \\
\hline Unclassified $^{*}$ & $.298(90)$ & & \\
\hline FRONSAC & $.033(10)$ & 0 & 1 \\
\hline GRAVES & $.116(35)$ & 0 & 1 \\
\hline LISTRAC & $.043(13)$ & 0 & 1 \\
\hline
\end{tabular}




\begin{tabular}{|c|c|c|c|}
\hline MARGAUX & $.126(38)$ & 0 & 1 \\
\hline PAUILLAC & $.116(35)$ & 0 & 1 \\
\hline POMEROL & $.109(33)$ & 0 & 1 \\
\hline STEMILION & $.162(49)$ & 0 & 1 \\
\hline STESTEPHE & $.073(22)$ & 0 & 1 \\
\hline STJULIEN & $.086(26)$ & 0 & 1 \\
\hline HAUTMEDOC & $.106(32)$ & 0 & 1 \\
\hline MEDOC & $.030 \quad(9)$ & & \\
\hline CABFRANC & 12.42 & 0 & 66 \\
\hline CABSAUV & 44.19 & 0 & 85 \\
\hline MALBEC & .30 & 0 & 10 \\
\hline VERDOT & 1.43 & 0 & 15 \\
\hline Merlot" & 41.66 & 8.0 & 100 \\
\hline SECWINE & $.036(11)$ & 0 & 1 \\
\hline PRODUCESEC & $.589(178)$ & 0 & 1 \\
\hline No SECWINE & $.374(113)$ & & \\
\hline $\mathbf{V}_{+1}$ & 95 & 92 & 98 \\
\hline$V_{.2}$ & 82.5 & 73 & 92 \\
\hline $\mathbf{P}$ & 29.51 & 8.92 & 302.56 \\
\hline
\end{tabular}

Note: The numbers in brackets give the number of observations in the sample for which a dummy variable equals one. The total number of observations is 302 .

- These variables comprise the base case in the estimating equation. 


\section{Appendix C: Cholce of Functional Form}

When determining the functional form for the price and quality equations, the two equations were analyzed separately. Five functional forms were considered for each equation: linear, log-linear (with the dumy explanatory variables untransformed), semi-log, reciprocal, and reciprocal square root. The models were compared using a RESET test, a heteroscedasticity (BreuschPagan) test and a non-nested test - the $\mathrm{P}_{\mathrm{E}}$ test of Mackinnon, White, and Davidson (1983).

\section{The Quality Equation}

The RESET and heteroscedasticity test results for different versions of the quality equation axe given in Table $c 1$. Neither of the tests could reject any of the five specifications. As a result, the linear specification was chosen since it is the most easy to interpret. The linear functional form was then compared to alternative specifications using the $P_{E}$ test. The $t-$ statistics from this test are given in Table C1. The log-linear model rejects the linear model at the 5 level, but not at the 1 level. However, if the log-linear model is the maintained hypothesis, the linear model rejects the log-linear model, even at the $1 \frac{8}{6}$ level, as shown by the results at the bottom of Table C1. As a result of these tests, the linear specification was chosen as most appropriate.

\section{The Price Equation}

When determining the functional form for the price equation, this equation was specified to include all the variables that 
would appear in a reduced form version of the price equation (that is, with expected quality substituted out, and the cross equation restrictions not imposed). The results in Table C2 indicate that the reciprocal square root functional form is the only functional form which is not rejected by the RESET test. Al1 the functional forms are rejected by the Breusch-Pagan heteroscedasticity test, but of these, the reciprocal square root form is the only one that is not rejected at the 1 level, and it is just barely rejected at the 5 level. These results indicate that the reciprocal square root functional form for the price equation may be the most appropriate. Taking the reciprocal square root model as the maintained hypothesis, this functional form was then tested against the other four specifications using a $\mathrm{P}_{\mathrm{B}}$ test. The test statistics for this test are also given in Table $\mathrm{c} 2$. While three of the four functional forms reject the reciprocal square root functional form at $5 \%$, none reject at $1 \frac{1}{\%}$. Given the above results, the reciprocal square root functional form was chosen as the most appropriate form for the price equation. 


\section{Table C1: Functional Form Tests -- Quality Equation}

$\begin{array}{lcc}\text { Functional Form } & \text { RESET Test } & \text { Heteroscedasticity Test } \\ \text { Linear } & .44 & 38.48 \\ \text { Log-Linear } & .57 & 39.25 \\ \text { Semi-Log } & .74 & 39.22 \\ \text { Reciprocal } & 1.10 & 40.02 \\ \text { Reciprocal Square Root } & .91 & 39.62 \\ & & 31\end{array}$

"The RESET test statistic is distributed as an F-statistic.

The Heteroscedasticity test statistic is distributed as a $\chi^{2}$ statistic.

Linear Model Compared to Other Models Using $P_{E}$ Non-Nested Test

Log-Linear Semi-Lop Reciprocal Reciprocal Square Root

t-Statistic $-2.58 *$ $-.68$

.69

.68

Log-Linear Model Compared to Other Models Using $\mathbf{P}_{\mathrm{E}}$ Non-Nested Test Linear $\underline{\text { Semi-Log Reciprocal Reciprocal Square Root }}$

$\begin{array}{lllll}\text { t-Statistic } & 2.78^{*} & 1.90 & -1.03 & -1.41\end{array}$

* Rejects at 5 percent.

** Rejects at 5 percent, but not 1 percent. 
Table C2: Functional Form Tests - Price Equation

Functional Form

Linear

Log-Linear

Semi-Log

Reciprocal

Reciprocal Square Root

Degrees of Freedom for Test

\section{RESET Test" Heteroscedasticity Test}

$177.18^{*}$

$70.70^{*}$

$57.93^{*}$

$78.10^{*}$

57.03*

$79.05^{*}$

$6.65^{* *}$

$67.19 *$

2.47

$51.77^{* *}$

1,264

36

"The RESET test statistic is distributed as an F-statistic.

${ }^{\mathrm{b}}$ The Heteroscedasticity test statistic is distributed as a $\chi^{2}$ statistic.

Reciprocal Square Root Model Compared to Other Models Using $P_{\mathbf{z}}$ Non-Nested Test

Linear Log-Linear Semi-Log Reciprocal

t-Statistic

$2.17^{* *}$

$2.26^{* *}$

$2.17 * *$

1.57

* Rejects at 5 percent.

** Rejects at 5 percent, but not 1 percent. 